BULLETIN Bulletin hispanique

HISPANIQUE Université Michel de Montaigne Bordeaux

117-1 | 2015

Les poètes des rhéteurs

\title{
Claves para la memoria colectiva en la obra de Rodrigo Lira
}

Nicolás Folch Maass

\section{(2) OpenEdition}

12 Journals

Edición electrónica

URL: https://journals.openedition.org/bulletinhispanique/3884

DOI: 10.4000/bulletinhispanique.3884

ISSN: $1775-3821$

Editor

Presses universitaires de Bordeaux

Edición impresa

Fecha de publicación: 1 junio 2015

Paginación: 325-344

ISBN: 979-10-300-0174-7

ISSN: 0007-4640

Referencia electrónica

Nicolás Folch Maass, «Claves para la memoria colectiva en la obra de Rodrigo Lira», Bulletin

hispanique [En línea], 117-1 | 2015, Publicado el 01 junio 2018, consultado el 12 febrero 2022. URL:

http://journals.openedition.org/bulletinhispanique/3884 ; DOl: https://doi.org/10.4000/

bulletinhispanique.3884 


\title{
Claves para la memoria colectiva en la obra de Rodrigo Lira
}

\author{
Nicolás Folch MaAss \\ Université Sorbonne Nouvelle, Paris III
}

Larticle porte sur la production poétique de Rodrigo Lira, l'une des figures emblématiques de la littérature chilienne pendant la période de la dictature. L'analyse de quelques-uns de ses textes tente d'expliquer la contemporanéité de sa poésie au-delà d'une lecture historique qui la restreindrait à l'époque de sa production.

Mots-clés : poésie chilienne, analyse textuelle, violence, mémoire collective.

El presente artículo se centra en la produccion poética de Rodrigo Lira, una de las figuras emblemáticas de la literatura chilena del primer periodo de la dictadura. El análisis de algunos de sus textos es una tentativa por explicar la contemporaneidad de su poesía, más allá de una lectura histórica que la limitaría a ser un testimonio de época.

Palabras claves: poesía chilena, análisis textual, violencia, memoria colectiva.

This article is focused on the poetic production of Rodrigo Lira, one of the emblematic figures of Chilean literature of the first period of Dictatorship. The analyses of some of his texts are a tentative explanation of the contemporaneity of his poems, beyond the Historic lecture that would be limited to be a witness of the time frame.

Keywords: Chilean poetry, textual analysis, violence, collective memory.

\section{El SONIDO ESTÁ EN LA LETRA ${ }^{1}$}

El artículo desarrolla una aproximación a la obra de Rodrigo Lira (19491981) a partir de dos conceptos claves para comprender el impacto de su recepción más allá del contexto de la dictadura chilena. En efecto, la memoria colectiva y la ironía como estrategia discursiva, aportan al análisis una alternativa

1. Rodrigo Lira, «Sermón de los hombrecitos magentas», Proyecto de Obras Completas, 2003, p. 140 . 
ante la abundante contextualización biográfica que ha asimilado a la poesía de Lira a un caso de archivo histórico o clínico.

Poeta chileno, Rodrigo Lira vivió durante los primeros ocho años de la dictadura suicidándose en 1981. Como poeta su figura ha sido inmediatamente relacionada con el periodo post Golpe de Estado del 11 de septiembre de 1973. Además, su ficha clínica de esquizofrénico y su fin trágico en el suicidio rodean al autor de la mítica figura del poète mandit.

La obra de Rodrigo Lira ofrece en consecuencia una serie de problemas que se cristalizan en la escaza y póstuma edición de su obra y el silencio de la crítica. Por lo general, los análisis sobre los textos de este poeta destacan las filiaciones con la obra de Nicanor Parra y Enrique Lihn o señalan su exceso referencial al contexto de la dictadura.

Lo que este artículo presenta es el análisis de algunos de sus textos cuyo lenguaje y símbolos se abren a una experiencia interpersonal y colectiva que desacraliza áreas del ámbito social representados, por lo general, desde el poder o la sumisión. De esta forma, el análisis investiga lo que actualmente se señala como una paradoja: el número creciente de lectores de Lira a pesar de la abundancia de referentes contextuales en sus textos que obstaculizarían una lectura plena.

\section{La Paradoja Rodrigo Lira}

La obra de Rodrigo Lira Canguilhem se caracteriza por ser neovanguardista, experimental y metapoética: la experimentación y una voluntad iconoclasta se manifiestan en sus textos. Además, la intervención del formato clásico de escrituración con elementos propios de la plástica e incluso de la dramaturgia, expresan su escepticismo ante las formas tradicionales de producción. Por ejemplo, Lira utilizó la performance para producir su poética de la parodia que solía aludir a personalidades de la literatura y la crítica chilena. A pesar de la imposibilidad de reproducir sus actos histriónicos en el papel, es posible identificar en sus poemas el escepticismo y la parodia ante el discurso literario. $\mathrm{Al}$ respecto podemos citar el trabajo intertextual que hace con un texto del antipoeta Nicanor Parra titulado "La Montańa Rusa». En el original, Parra advierte al lector que no se le deben exigir explicaciones al autor si su poesía produce sangre de nariz debido al choque que pueda resentir. Lira responde irónicamente y escribe en su poema «78: Panorama poético santiaguino o "Los jóvenes tienen la palabra" -crónica de época-»:

$$
\begin{aligned}
& \text { hasta donde llegan } \\
& \text { los datos del autor, } \\
& \text { nadie ha sido atendido aún } \\
& \text { por hemorragias nasales y/o } \\
& \text { bucales en las postas }[. . .]{ }^{2}
\end{aligned}
$$

2. Rodrigo Lira, «78: Panorama poético santiaguino o "Los jóvenes tienen la palabra" 
Pero, la recepción de la obra de Lira en los comienzos de los ochenta no solo se vio afectada por los conflictos personales que el poeta mantuvo con el círculo literario, sino además por su escasa publicación ${ }^{3}$. En efecto, sus dos libros publicados son póstumos: Proyecto de Obras Completas (1983, 2003) y Declaración Jurada (2006). Otro hecho que dificultó el proceso de recepción, fue la pronta desaparición del autor. Este factor bio-bibliográfico ha mantenido su obra en el círculo de los iniciados y sus textos por mucho tiempo ensombrecidos por el culto al autor. Roberto Merino señala:

En 1984, Enrique Lihn y un grupo de amigos de Lira publicaron el libro póstumo Proyecto de obras completas, conservando la selección de textos que el autor había hecho para la carpeta mencionada al principio de esta nota. En casi veinte años el libro ha tenido oportunidad de circular, ser fotocopiado, llegar a las librerías de viejos $y$, virtualmente, desaparecer. Le ha creado, también, al poeta, una red de lectores tan incondicionales como subterráneos. Se ha transformado, por decirlo así, en un libro de culto, difícil de conseguir y, en ocasiones, extremadamente caro. A Lira mismo -poeta de fotocopias y lecturas públicas- le hubiera sorprendido esta situación. ${ }^{5}$

Actualmente, algunas fotocopias inéditas continúan transitando de la misma manera subterránea entre los lectores más avisados y afortunados. Paradojalmente la recepción de estos textos y la fidelidad de los lectores contradicen al grueso de la crítica que desde entonces señala problemas en la recepción de su poesía. Se han escrito líneas para intentar contrarrestar esta percepción negativa, pero por lo general se trata de panegíricos que mantienen el culto a la persona y, de esta forma, permiten la predominancia del autor sobre sus textos:

Mucho se ha escrito y poco se ha dicho realmente de la poesía de Lira. Lo que marea de la figura de este poeta es su vida en la crítica periodística: sus problemas psiquiátricos, sus indecisiones, sus inconstancias académicas... su suicidio.

Son muy pocas las monografías o artículos especializados, apuntados a la escritura de Lira. Incluso en ciertas antologías no está incluido. ${ }^{6}$

-crónica de época-», Proyecto de Obras Completas, 2003, p. 105.

3. Durante su vida, Lira distribuye sus textos al círculo de personas próximo, fotocopiados o por medio de envíos a concursos de poesía. Una de las revistas que entabla relación con el joven poeta es $L a$ Bicicleta, revista alternativa y opositora al régimen de A. Pinochet. En un artículo póstumo de esta revista (Antonio De la Fuente, «Trinitariamente pergueñando al infinito», La Bicicleta, $\mathrm{n}^{\circ}$ 19, p. 36) dedicado a la poesía de Lira, se destaca la afirmación «Rodrigo era poeta», en contraste a lo que algunos escritores solían decir de él.

4. Para referirnos posteriormente a estos dos libros, utilizaremos las abreviaciones P.O.C. (Proyecto de Obras Completas) y D.J. (Declaración Jurada).

5. Roberto Merino, «Nota a la segunda edición», en Rodrigo Lira, Proyecto de Obras Completas, pp. 10-11.

6. Gonzalo Rojas C., "Dos poetas de los ochenta: Juan Luis Martínez y Rodrigo Lira. Autorreferencia y fragmentación ». In Cyber Humanitatis [En ligne], Universidad de Chile. [Page consultée le 30 avril 2012]. Disponible sur :

http://www.cyberhumanitatis.uchile.cl/index.php/RCH/article/viewArticle/5647/5515 
Como ya señalamos, la crítica reprocha problemas en la receptibilidad de su obra. Se atribuye este problema al uso particular del lenguaje y a la abundancia de referencias extremadamente anecdóticas y ligadas a la época de la dictadura. Además, Lira no publica de manera tradicional y bajo formatos convencionales lo que repercute en la ausencia de referencias sobre su creación. Incluso cuando se reconoce el valor y las características de su poesía, se expresan dudas sobre la receptibilidad y los problemas que sus escritos inspiran. El poeta Enrique Lihn, en su prólogo de P.O.C., expresa la dificultad a la que futuros lectores se verán enfrentados por desconocimiento de los detalles y las circunstancias biográficas que contextualizan al sujeto de la enunciación. Es lo que señala bajo el término de "oscuridades de referencia» ${ }^{7}$. Paralelamente, Grinor Rojo, en el prólogo de D.J., expresa su perplejidad ante la vigencia de textos extremadamente circunscritos a un locus específico (Santiago) y a la época del triunfalismo pinochetista. Rojo intenta, en ese mismo prólogo, una respuesta a la paradoja a partir de una supuesta evolución coherente o "cable de continuidad» entre lo que significó el Golpe de Estado de 1973 y «[...] el espíritu reinante entre muchos jóvenes actuales $[\ldots] »^{8}$. Dicha hipótesis merece ser estudiada. Sin embargo nos parece riesgosa por dos razones. Primero, por la dificultad para establecer un diagnóstico que dé cuenta del estado anímico de la juventud chilena actual que establezca similitudes con el de la época de Lira. Segundo, esta hipótesis resta importancia al efecto anímico que los textos poéticos puedan provocar en el lector. Es decir que en el caso específico de Lira, su obra dependería, más que de sus efectos estéticos, de un estado anímico $a$ priori en los lectores.

En consideración de lo anterior, pensamos que es posible aportar algunas claves de lectura de la obra de Lira que expliquen su vigencia a partir de los textos mismos. En consecuencia, analizaremos algunos de ellos a la luz de sus posibilidades simbólicas con respecto a una semiotización de la violencia presente en este autor.

\section{LoS SÍMBOLOS DE LA VIOLENCIA Y LA MEMORIA COLECTIVA EN LA OBRA DE LIRA}

Es posible que en el caso de la obra de Lira, la abundancia de referentes contextuales haya guiado a la crítica a una lectura de interpretación del referente inmediato, condicionando así sus posibilidades simbólicas ${ }^{9}$. Un texto como «Poema -u oratorio- fluvial y reaccionario» puede ser analizado según su contexto por su aparente implicación con el marco político inmediato:

7. Enrique Lihn, «Prólogo», en Rodrigo Lira, Proyecto de Obras Completas, p. 17.

8. Grinor Rojo, «Prólogo», en Lira Rodrigo, Declaración Jurada, 2006, p. 17.

9. Umberto Eco en L'ouvre ouverte (1979) establece que en toda experiencia estética, el placer provocado se origina por una confrontación a una serie de variantes de experiencias anteriores. Es decir que se moviliza una base común de experiencias pasadas en una obra de arte y se pone en marcha una transacción entre la historia de los individuos y el sujeto representado. Sin embargo, dicha transacción puede permanecer oculta y negada, incluso prohibida, durante ciertos periodos de tiempo. 
$\$ 1$.

Estés un Pohéma - uh Ohra Torio - Re'acsionario. Es un $\mathrm{tr}_{\mathrm{a}}$ a jo sobre la sos Pecha que ahsaltó al Podéta - que aquí se saca la caréta - de que los «dados» estuvieran o estuviesen «cargados». ¡Cosa tremenda!, estés un DMente testo torpe ü de Liránte. Dicho testo - este mismito - denuncia a las ahuTory-dades quecsisten aún mentes con Taminádas por los viros de lo No-Re' acsionario ü tiene a bien sol \& citar se tenga a bien Re' acsionar en con Secuéncia. ${ }^{10}$

Ilustramos con este fragmento las claves evidentes que invitan a una interpretación no textual, sino contextualizada en la época de la dictadura. Textos llenos de un lenguaje experimental que enmascaran al sujeto tratado y otorgarían así un señalamiento fragmentario de la situación cultural y política inmediata. De esta forma, se interpretará el trabajo de lenguaje «liriano» como una estrategia discursiva que no tiene más razón que la filiación con la antipoesía de Nicanor Parra y con las vanguardias literarias. Por otra parte, las referencias a los «dados cargados» y al sector reaccionario aludido, son fácilmente atribuibles según el prisma de la represión y la censura militar. En consecuencia, estaríamos ante un fragmento que rinde cuenta con ironía de un destino forzado en el que nada queda al azar por los poderes fácticos que representan al sector reaccionario (el poder dictatorial). Este análisis de la obra de Lira en el que se explica un contexto basado en el texto es lo que ha generado sus limitaciones interpretativas. Lihn se adhiere a este análisis cuando advierte en su prólogo de 1983: "Creo, y esto es válido para cualesquiera de los escritos reunidos en el presente libro, que deben releerse con relación a la situación aún vigente en que fueron escritos» ${ }^{11}$.

La paradoja gravita precisamente en la permanencia de su obra en lectores que incluso no poseen el conocimiento de esa «situación» que experimentaron los poetas bajo la dictadura. Los supuestos obstáculos que un lector contemporáneo tendría para apreciar una obra que depende de su contexto inmediato parecen no afectar en su recepción.

En este sentido, observamos en la obra de Lira la manifestación de una estrategia que persiste en la transmisión simbólica de la violencia cuyo poder justificaría su contemporaneidad. En efecto, es posible identificar en ella ciertas recurrencias a la alienación social, al abuso de poder y al sometimiento del individuo que tienden un nexo con la memoria colectiva ${ }^{12}$. Al respecto, un

10. Rodrigo Lira, «Poema -u oratorio- fluvial y reaccionario», Proyecto de Obras Completas, p. 147.

11. Enrique Lihn, «Prólogo», en Rodrigo Lira, Proyecto de Obras Completas, p. 18.

12. Como lo señala Paul Ricoeur (2000) en La mémoire, l'histoire, l'oubli, uno de los recursos literarios que permite la identificación y la perduración del trabajo de la memoria en el texto literario, es la analogía. La identificacion entre subjetividades gracias al «como»; es decir «el otro como yo». Ricoeur indica, con respecto a la intersubjetividad y a las entidades colectivas, que es por medio de la identificación entre los diferentes egos que la memoria colectiva resurge : "À la faveur de ce transfert analogique, nous sommes autorisés à employer la première personne à la forme plurielle et à attribuer à un nous - quel qu'en soit le titulaire - toutes les prérogatives de la mémoire [...]» (p. 145). En este sentido postulamos que la simbolización de la violencia en Lira 
factor clave es el lenguaje utilizado dentro de una estrategia discursiva coherente, para establecer el modo $o^{13}$ en que se transmiten estos símbolos.

Ahora bien, si nos focalizamos únicamente en el tono intimista y testimonial de la obra de Lira, tendremos elementos que por sí solos no justificarían la paradoja del impacto de su obra. El riesgo es detenernos en la anécdota y perder de vista el texto para terminar viendo al autor en sus circunstancias reales. No obstante, es a través del empleo del lenguaje familiar y del uso de la ironía como el discurso de Lira se libra del contexto dictatorial y la aproximación del lector hacia el espacio del hablante trasciende.

La función del lenguaje en la obra de Lira -quien más que un poeta se consideraba «un diestro operador del lenguaje» ${ }^{14}$ - con respecto a la memoria colectiva es, si no central, importante para dar fuerza a los símbolos colectivos que se encuentran en los textos. Es el tono intimista en su poesía y la abundancia de anécdotas transmitidas en un lenguaje familiar, conjugados con el empleo de la ironía, lo que permite la activación de la memoria colectiva. La experiencia significativa (su recuerdo personal) y el poder simbólico, se asocian y posibilitan la trascendencia a un nivel colectivo. Así, la anécdota es importante, solo en la medida que esta sea transmitida con un lenguaje cargado de símbolos que se abran a la colectividad.

En el fragmento de «Poema -u oratorio- fluvial y reaccionario», podemos advertir que la individuación del hablante se expresa de manera irónica en la figura del "Podéta» que se desenmascara como enunciador. La connotación irónica en la alteración del vocablo «poeta» define una posición de irreverencia, de burla o crítica hacia el status literario. La ironía ofrece una aproximación entre el ego del lector y el texto desde el momento en que el lector es capaz de decodificar «Podéta» como neologismo irónico. Esta estrategia establece una crítica por oposición subyacente ${ }^{15}$ a la que el lector llega como cómplice del autor. La estrategia discursiva aquí explicitada sugiere la dirección del análisis textual. Por medio de este análisis demostraremos la existencia de una fuente «metapersonal» en los textos de Lira que comunica con la memoria de la violencia silenciada por el discurso histórico oficial chileno.

potencia su sintonía con un amplio universo de lectores.

13. Andrew Barash (2006), en su artículo «Qu’est-ce que la mémoire collective ? Réflexions sur l'interprétation de la mémoire chez Paul Ricœur», agrega que para que la analogía de Ricoeur sea efectiva en el reconocimiento transubjetivo, tiene que intervenir un lenguaje que incorpora símbolos de fuerte significancia colectiva. De esta manera, el lenguaje constituye una fuente «metapersonal» que une la memoria de un pasado lejano a futuras generaciones.

14. Roberto Merino, «Nota a la segunda edición», en Proyecto de Obras Completas, p. 10.

15. Danielle Forget (2001) en su artículo "Lironie : stratégie de discours et pouvoir argumentatif», señala que la ironía es un recurso que permite tomar distancia del sujeto tratado y se vuelve crítica por oposición. Esta oposición latente se revela en el acto de reconocimiento de la ironía por parte del lector. 


\section{ANÁLISIS DE TEXTOS: \\ EL RECHAZO A LA DISTORSIÓN DE LA MEMORIA}

En los textos de Lira hay una ausencia de lirismo a favor del lenguaje familiar, hecho que potencia la representación e inmediata desestructuración de los códigos sociales colectivos. Lira privilegia de esta manera la aparición de una memoria oculta detrás de la historia oficial y del lenguaje que la comunica. En sus textos el lector se encuentra frente a un lenguaje reconocible, pero manipulado para exponer su esterilidad. Se trata de la confrontación con un lenguaje sin contenido real para la comunidad, incapaz de reenviar un fiel reflejo en el que ella se reconozca. Única posibilidad de reencuentro: los símbolos portadores de una memoria colectiva acallada. Lihn lo intuye al referirse a dos poemas de Lira, pero no se detiene lo suficiente como para darle una lectura más amplia a esta dimensión:

«Testimonio» es una especie de Lazarillo de Tormes psicoanalítico que hace pasar el tema de la marginalidad por una serie de lugares: la pobreza, la droga, el sexo y el suicidio. Este testimonio personal y generacional se reitera, de otra manera, en «Topología del pobre topo», donde la caricatura escrita es llevada a la farándula. ${ }^{16}$

Los textos de Lira, están impregnados de símbolos que trascienden lo textual y participan de una experiencia transubjetiva por medio de la semiotización de la violencia. Gracias a este recurso discursivo, Lira transmite en sus textos la experiencia de una alienación forzada o condicionada del individuo. Por ende, su poesía profundiza y refleja la experiencia universal de la represión y la precariedad en la vida contemporánea que van más allá del caso chileno. Sin duda, no se pueden desechar de la obra aquí estudiada las referencias directas al contexto propio de la dictadura de Augusto Pinochet. Estas existen, pero en menor grado de lo que se ha pretendido. El poema «A modo de explicación. Uno: Cantinela musitada» es un ejemplo de la contextualización denotada en estos versos:

Ya no queda nada: se cortó la leche, se apagó la llama,

Se quemó el asado, se acabó la vela, despertó la guagua,

Se durmió la mina, se murió la abuela, lloró una muchacha. ${ }^{17}$

El lector consciente e ilustrado podrá leer aquí la alusión a lo que se denomina como «el apagón cultural» que provocó la censura durante la dictadura. Pero ciertamente, no es necesario conocer el contexto para comprender que Lira compuso una obra que utiliza un habla familiar que enuncia la precaria

16. Enrique Lihn, «Prólogo», en Rodrigo Lira, Proyecto de Obras Completas, p. 20.

17. Rodrigo Lira, "A modo de explicación. Uno: Cantinela musitada", Proyecto de Obras Completas, p. 137. 
situación de un hombre en soledad que va «trazando surcos sobre las arrugas de la cara larga / de la angosta cara entre cordilleras al lado del agua» ${ }^{18}$.

En consecuencia, nada señala exclusividad epocal en los textos de Lira. Ciertamente hay que dirigir el análisis hacia lo que los textos connotan. Con respecto a la simbolización de actos de sometimiento o alienación del hombre, los estudios recientes publicados sobre la historia y la sociedad chilena concuerdan en señalar el divorcio entre la historia oficial y hechos de represión cruenta que la memoria revela como aspectos obviados por el discurso oficial ${ }^{19}$.

En la obra de Lira destaca la reiteración de un rechazo al lenguaje oficial y la presencia de una institución que oprime al hombre, que no es exclusiva de una época, sino que sería característica del ejercicio del poder de manera histórica en Chile. En efecto, la imagen oficial que incluso el dictador utilizó para justificar la represión es que Chile ha sido un país de larga tradición democrática, de respeto constitucional en paz. En este sentido, el discurso oficial después del Golpe de Estado de 1973 establecía que se intervino militarmente para defender esta tradición democrática del imperialismo soviético ${ }^{20}$. La historia oficial refuerza así una imagen de país en el que el periodo de Pinochet sería un paréntesis de violencia y represión. Esto equivale a la negación o el olvido de una serie de sucesos ocurridos en la historia chilena que siempre han sido resueltos a favor de quienes no han dudado en utilizar y legitimar la violencia para sus fines:

Este poder oscuro, persistente, obtuso, en alianza permanente con las fuerzas armadas, cuando ha creído en riesgo real su dominio [...] ha reaccionado siempre de manera brutal, justamente poniendo en acción cada vez su brazo armado: la matanza de obreros y sus familias [...] el golpe militar de 1973 [...]. Pero cuando el horizonte aparece despejado [...] ese mismo poder se repliega como fuerza bruta y deja que actúen sus discursos $[\ldots] .^{21}$

Dos versiones de la identidad se oponen: una oficial, republicana y ejemplar; otra soterrada que rememora una violencia institucional "regularizada» y ejercida por un grupo de poder sobre el resto de la sociedad. La obra de Lira, establece un puente que actualiza una memoria remota: aquella de los opresores y los oprimidos. Entendemos que en la poesía de Lira lo que se transmite gracias al desplazamiento del ego es esta experiencia olvidada por los canales institucionales del relato histórico. En este sentido, el lector comprende su posición como individuo porque es capaz de verse reflejado en los textos

18. Ibid. p. 137.

19. Entre otros estudios, remitimos al lector al notable trabajo de investigación colectiva bajo la direccion de de Rafael Gaune y Martín Lara, publicado bajo el título de Historias de Racismo y Discriminación en Chile, 2009.

20. Cfr. Jorge Baeza C., «Referencias para un análisis del discurso del gobierno militar chileno sobre el movimiento estudiantil universitario: 1973-1980», en Literatura y Lingüística, 2004, pp. 253-286.

21. Leónidas Morales, "Joaquín Edwards Bello: Crónica y Crítica de la Vida Cotidiana Chilena», en Revista Chilena de Literatura, 2009, p. 75. 
de Lira, por oposición al reflejo deformado que reenvía el discurso oficial de identidad histórica. El lenguaje, es aparentemente simple, familiar. Esto se refuerza, como advertimos, con el hecho anecdótico, lo que confiere a los textos un grado íntimo que acerca al lector con el sujeto de la enunciación. La estrategia discursiva favorece al desplazamiento y reencuentro de los egos entre el poeta y el lector por medio del texto.

Para ilustrar esta estrategia, presentamos el siguiente fragmento del texto «Curriculum Vitae»:

\section{ADVERTENCIAS}

El postulante no dispone de una 'personalidad agresiva'.

El postulante en general no es todo el tiempo una persona 'dinámica'.

El postulante no tiene televisión, ni teléfono, ni 'movilización propia'

Como se indicó, el postulante no tiene facilidad sobresaliente para integrarse fluidamente a grupos de trabajo en equipo.

Aparte de algunos ex alumnos del Campus Macul, y una mayoría de escritores, el postulante tampoco mantiene un nivel digno de consideración de relaciones sociales: no es una persona 'bien relacionada'.

El postulante, sin embargo, no es nada de tonto. ${ }^{22}$

Este fragmento revela la manera en la cual Lira implica una experiencia estética que moviliza a una memoria colectiva mucho más amplia; una memoria que no responde únicamente a los parámetros de la dictadura militar. Si bien, el texto "Curriculum Vitae» es eminentemente testimonial, es necesario leer dicho testimonio como un palimpsesto de las fórmulas de la administración, del Estado, de toda sociedad burocratizada y del individuo alienado en dicha burocracia.

Esta lectura sobrepasa al orden impuesto por los militares en Chile a partir de 1973 y el tono intimista que se observa en el texto tiene mérito en ello. Obviamente, existe la metonimia estructurante del clima represivo militar, que ven sus prologuistas con respecto a su época; pero el poder simbólico va más allá. Los textos de Lira no estimulan la memoria excluyente, sino a aquella incluyente a varias generaciones. La fuerza de la memoria en los textos de Lira reside precisamente en aquellos shifters que imprimen a sus textos un sello íntimo que evita el anonimato del 'nosotros' o de la forma impersonal de los textos de historia. De esta manera, la memoria vive, se activa y permite reconocerse en ella ${ }^{23}$. Incluso las advertencias del texto, una serie de enunciados impersonales, se vuelven personales debido al sentido irónico que refuerza la participación de un sujeto bien presente a pesar del uso de la tercera persona. Por ejemplo, la línea que advierte "El postulante, sin embargo, no es nada de tonto», tanto por la ironía significada, como por el lenguaje familiar empleado, se desplaza hacia el otro lector y lo vuelve cómplice, como él, su semejante reivindicado. Este "Curriculum Vitae» textualiza la realidad de una humanidad 
enfrentada a las necesidades pecuniarias de obtener un trabajo y a la alienación dentro de la administración.

En el siguiente fragmento del poema «Ela, Elle, She, Lei, Sie», las referencias a una realidad extratextual son abundantes y el ego se desarrolla en la exposición de un juego entre el «Yo» y la tercera persona:

Está tomando créditos de fundamentos sicosociobiológicos y filosoficales de la educaciónica.

Estará estudiando geografía la geografea, en el campus oriente de la ucé, seguirá yendo a misa la pata peluda.

Dejó aquí su pijama japonés este mediodía y le compré mentolados cigarettes antes de dejarla en la micro. ${ }^{24}$

Todo este poema está estructurado según la relación del hablante con su sujeto poético, que existe en el texto como un medium entre el texto y la realidad factual («Dejó aquí su pijama»). La figura femenina no puede escapar de la relación establecida entre el que escribe («Yo») y su contexto, porque ella está en todos los planos evocados (espiritual, intelectual y físico). La relación con la realidad enunciada se fusiona de manera dantesca, porque su síntesis (mujer - realidad - Yo) crea un efecto de espanto y confusión ante el sujeto de la enunciación. De hecho, en otros versos del mismo poema, lo grotesco horroroso persiste: «y las vértebras se movían solas», «y perdí la mano / Manco, cómo podría masturbarme», "La araña se come al araño y la abeja reina mata a los zánganos». Además, la fusión de realidades se materializa incluso en el lenguaje. Así, por contigüidad espacial, la mujer que estudia "geografía» es luego calificada de "geografea». Este neologismo que actualiza la articulación monstruosa "yo -mujer- realidad» refleja un precario equilibrio en el que un contexto frívolo (su objetivación) opera en el poema modificándolo. El resultado es la violencia del lenguaje que se expresa en neologismos propios de un bestiario para referirse a la mujer («la pata peluda», "geografea»). Aún más, esta confusión, resultado de la amalgama antes mencionada, afecta al plano intelectual y lo vacía de toda capacidad significativa, para luego llevarlo al plano del absurdo. Así, las palabras compuestas en «sicosociobiológicos y filosoficales de la educaciónica» denotan la ironía de una actividad dominada por el logos, pero sin especifidad («sico-», «socio-» $\mathrm{y}$ « bio-» se vuelven prefijos equivalentes para el campo universitario). La ironía es más explícita y despreciativa con la utilizacion del sufijo «-ales » (corriente en el lenguaje de la crónica policial) para el adejtivo "filosófico». De esta manera, la fea realidad, confusa y amenazante para el hablante, irrumpe en el texto y contamina al lenguaje, invirtiendo la relación entre significante y significado hasta una equivalencia inoperante, monstruosa o absurda.

Se aprecia entonces el acento en las circunstancias triviales - no exclusivas de la época de la dictadura- que el sujeto enuncia como por ejemplo, el vivir una relación de pareja, con toda la alteración y cuestionamientos sobre el otro que ello le significa al hablante («estará estudiando geografía», «seguirá yendo

24. Rodrigo Lira, «Ela, Elle, She, Lei, Sie», Proyecto de Obras Completas, p. 46. 
a misa», «dejó aquí su pijama japonés»). El texto desarrolla una lógica cercana a la deliberación y a la fabulación, lo que acerca el ego del hablante hacia el otro gracias a la imaginación y a la cercanía dialectal del lenguaje (el familiar «ucé» para designar las siglas de la Universidad Católica o «micro» en lugar de microbús).

Sin embargo, al parecer, Lihn y la mayoría de los críticos posteriores señalan precisamente este aspecto como una dificultad para la legibilidad de su poesía. Lihn se refirió a la "comunicabilidad tribal» como uno de los obstáculos a la recepción de la obra. Pero, en realidad, es un elemento que potencia el traspaso de la memoria en la obra de Lira. Así, por ejemplo, con la "pata peluda» que va a "misa», alude a un rito religioso intrínsecamente ligado a las prácticas sociales chilenas. La relación que se establece entre "geografea» y la voz popular "pata peluda» (que asimila a la tercera persona con un peligro ambivalente: mujer arácnida), prefigura la dimension de lo grotesco integrado en el lenguaje popular y de lo pernicioso de un sector social asimilado a prácticas institucionales conservadoras como el rito de los domingos en la iglesia o de la educación universitaria católica. Al mismo tiempo, la alteridad ligada a este sector social representa una profunda complejidad que se traduce en una figura incierta y distante, que está más allá («antes de dejarla en la micro», «seguirá yendo a misa»). Estos son ejemplos de las ocurrencias del lenguaje familiar que permiten dar con símbolos colectivos de una violencia institucional subyacente.

El siguiente extracto del poema de largo aliento «Testimonio de circunstancias» confirma una posición de rechazo hacia la institucionalidad y sus métodos alienantes:

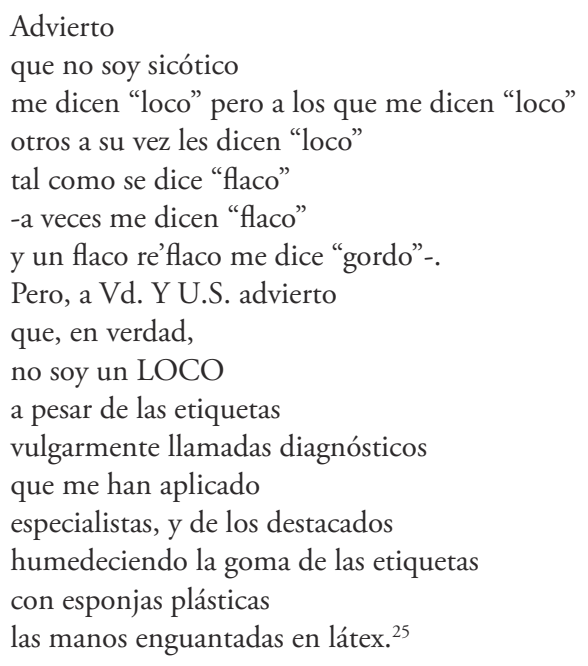

Los versos que hablan de las «etiquetas vulgarmente llamadas diagnósticos» denotan un rechazo a la autoridad desde el lenguaje. Lira confronta al lector de este y otros textos con la esterilidad de un discurso sin contenido real para

25. Rodrigo Lira, «Testimonio de circunstancias», Proyecto de Obras Completas, p. 57. 
la comunidad, pero que reenvía un reflejo («diagnósticos») distorsionado de la sociedad («a pesar de»). En este fragmento los símbolos portadores de una memoria colectiva acallada por un discurso oficial emergen en las imágenes médicas y la multiplicación de materias artificiales. La violencia simbolizada opone el discurso oficial a la memoria y permite reconocer la operación regularizadora y coercitiva de la misma («humedeciendo la goma de la etiquetas / con esponjas plásticas / las manos enguantadas en látex»).

La esterilidad nominal que expone este texto se refleja en la equivalencia entre el lenguaje familiar y el llamado lenguaje científico que supone la voz de una autoridad dentro de la sociedad. De esta forma Lira desmitifica al lenguaje de autoridad por la sinonimia entre "sicótico» y la interpelación familiar «loco» que a su vez equivale a las voces coloquiales "flaco» $\mathrm{y}$ "gordo» que nada dicen en realidad. Se expresa así una perturbación en la función representativa del lenguaje y los límites entre significantes se han vuelto confusos y aún más arbitrarios. Con esta desacralización lingüística se interpela a la memoria colectiva de la sociedad contemporánea dominada y tradicionalmente jerarquizada, con una élite cuyo discurso se oficializa en «diagnósticos». Es esta simbolización del poder y el ejercicio de la violencia por parte de una elite («especialistas», «destacados») lo que se evidencia con mayor fuerza en los textos de Lira y lo que actualiza un estado de la condición humana en la sociedad tecnocrática y burocratizada.

Por otra parte, la ironía como estrategia discursiva corresponde a una actitud comunicativa que implica a todo el poema. El tono irónico con el que el hablante enuncia traspasa todo el texto. La estrategia no funciona en un verso determinado sino en el complejo lingüístico global. Así, en este fragmento la circunlocución de la cual deriva la asociación entre "psicótico - loco - flaco gordo» con las «etiquetas» o «diagnósticos» problematiza la actitud del hablante $\mathrm{y}$ es el lector quien resuelve y se desplaza hacia el ego irónico representado en el texto. La ironía de que "psicótico», «loco», "gordo» o «flaco» terminen significando lo mismo, es decir un diagnóstico errado, se vuelve crítica por oposición y el lector comprende la ironía solo si comprende la crítica que engloba.

En «Testimonio de circunstancias», Lira evoca la memoria colectiva, cultural y socio-económica, a partir de la experiencia personal y la utilización del lenguaje y el paisaje urbano como expresión cultural de la impostura y enmascaramiento de la verdad:

\author{
Advierto ¡ay! que tampoco soy un poeta pobre \\ las Musas no me han bendecido \\ con una pobreza solemne \\ de sietes y brillos en el terno oscuro \\ de cuello y puño deshilachados \\ y feas corbatas angostas pasadas de moda \\ [...] \\ De modo que no soy poeta pobre \\ aunque a veces ande por ahí mirando
}


comida, con hambre y sin plata

aunque no haya podido sacar de ese prostíbulo

de la calle San Camilo cerca de Santa Isabel

a una chillaneja que anduvo por el ambiente

por falta de plata

pues como no soy católico

no me interesé en rescatar de ahí mismito

una imagen de la Santísima Virgen

que se venera al lado de la caja fuerte

ni sacar un librito por falta de plata

ni comprar libros nuevos

y porque sé de la pobreza que no es pose

la temo y la respeto como para ponerme a hacer gárgaras o gorgoritos

con la palabrita

o describir sus gárgolas trompeteantemente

engolando la voz al leer la Oda subsecuente

-las audiencias suelen emocionarse:

¿mala conciencia

en las audiencias? ${ }^{26}$

El sujeto se enuncia a lo largo del fragmento con un lenguaje familiar que da mayor cercanía sobre el tema que expone: la pobreza y su impostura. Así, el lector aprecia la complejidad de la paradoja, llena de matices, cuando el poeta se reconoce como alguien que no es ningún "poeta pobre», imagen sacralizada por la tradición, sino alguien que finalmente conoce la pobreza real. Sin embargo, el texto problematiza la tensión entre los extremos sociales gracias al advervio «a veces». De esta manera, la experiencia de la pobreza, cotidiana y circunstancial ("a veces ande por ahí»), le otorga al hablante mayor libertad para rechazar la impostura del "poeta pobre» que niega ser. Conocimiento que el hablante no solo posee por vivir la experiencia real a veces, sino que además por frecuentarla en lugares que sin ser periféricos, están alejados del progreso de la capital. Esta posición de rechazo a la caricatura no confronta la realidad del pobre al que no lo es, sino que agrega matices suficientes y reconocibles para que un lector universal los reconozca como cercanos a su realidad. En este sentido, «la temo y la respeto» es una confesión que forma paradigmáticamente una unidad de sentido con el acto fallido de intentar sacar de la prostitución a una mujer.

Nuevamente Lira juega con la capacidad de nominación y la función referencial del lenguaje estableciendo una fina distinción entre el adjetivo "pobre» aplicado culturalmente a "poeta " y los sustantivos "pobre» $\mathrm{y}$ "pobreza». El hecho de no ser el poeta pobre de la Bohemia literaria, pero conocer lo que es realmente la pobreza, no supondría un obstáculo (más bien lo contrario) para reconocer una oposición: la de la verdad frente a las etiquetas o imposturas ${ }^{27}$.

26. Rodrigo Lira, «Testimonio de circunstancias», Proyecto de Obras Completas, p. 68-69.

27. Por este motivo, el hablante propone su propia imagen como definición de poeta a partir del contraste significado en la cláusula «a no ser que ser un poeta / sea». El texto ofrece entonces una dialéctica contrargumentativa de lo que es la impostura: el hablante no es poeta, a no ser que poeta sea «ser un payaso», «ser un espectro», «ser un desubicado, inadaptado / no mal parecido, de léxico extenso», «o sea ser simplemente alguien / con una forma larga de mirar», etc. 
El ambiente descrito con detalles como el lugar o su decorado insinúa en sí una precariedad y el hablante asume finalmente esa doble precariedad: la suya y la del paisaje marginal urbano. De esta forma, sin ser poeta pobre, pero sin dinero para pagarse libros ni comida y sin ser católico, él ingresa a prostíbulos donde otra negación se formula: la impotencia de no poder sacar del «ambiente» a una joven sureña por falta de dinero. La negación, el rechazo, se formula aquí con la fuerza acumulativa de símbolos colectivos. En primer lugar, el lenguaje familiar en sí mismo actúa como un símbolo en el que todos se reconocen («a veces ande por ahí», «sin plata», "ahí mismito»). En segundo lugar, la ambigua expresión "por ahí» denota aquellos sitios que la colectividad destina a un lugar oscuro e impreciso en la urbe, con un lenguaje popular lleno de eufemismos («anduvo por el ambiente») que alude a un mundo con reglas diferentes o fuera de la ley, como los prostíbulos. Hambre y prostitución se añaden al campo significante de "pobre» y de "pobreza», además del provincialismo, que supone un distanciamiento del desarrollo de la capital y que es significado con el adjetivo "chillaneja».

Los símbolos de la marginalidad desestructuran aquí la modernidad que supone la ciudad, pero que no corresponde a la realidad del sujeto: es decir un poeta que no es el poeta pobre de la fórmula consabida, pero que conoce la pobreza y la serie de negaciones que causa dicha pobreza. Nuevamente, la fuerza de los símbolos colectivos ya citados y otros, como «la Santísima Virgen» y los topónimos «la calle San Camilo cerca de Santa Isabel», provocan el desplazamiento del lector hacia el hablante por medio del reconocimiento colectivo de modismos e imágenes. Además, la identificación detallada de la urbanización moviliza la mímesis de todo paisaje urbano y el lector puede percibir la universalidad de esta falsa imagen de la modernidad o de su contraste. La ironía refuerza dicho desplazamiento para lograr la analogía de sentirse como el otro. La suntuosidad y la exageración que encierra el neologismo «trompeteantemente» ayudan en este sentido a transmitir la burla hacia aquel discurso paternalista y efectista de la tradición cultural y literaria que el mismo hablante critica. En efecto, este neologismo y el uso de la mayúscula en "Oda» (que alude al canon como institución) provocan el contraste carnavalesco de lo grotesco al querer comunicar con un discurso (en este caso, canónico poético) que distorsiona la real pobreza. Por otra parte, vale la pena hacer referencia a la burla de Lira hacia el oficio del poeta popular y oportunista en este verso («engolando la voz al leer la Oda subsecuente»).

Finalmente, la pregunta con que se cierra este fragmento es la confrontación con la actitud colectiva de sumisión ante un relato o discurso oficial. La graduación de la miseria en diferentes niveles (personal, social, cultural) concluye con un cuestionamiento que supone la negación de esta realidad marginal y sin eufemismos. Una realidad de la que se conoce la existencia sin aceptarla como propia. El hablante se pregunta entonces si la emoción de la «audiencia» es producto de la mala conciencia. 
Complementamos lo anterior con el texto "Cosas que suelen ocurrir en eternos instantes». El oxímoron del título ofrece un núcleo semántico que tensiona al poema en su estructuración. Así el instante al que el hablante se refiere se ofrecerá en diversas posibilidades enunciativas que expresan una voluntad por captar la immediatez o al menos acercarse al instante presente; ejercicio de la fatalidad frente a la posibilidad del $\operatorname{ser}^{28}$ :

Roberto cae se estrella en el suelo de baldosas y muere.

Roberto resbala por ocho pisos de caja-escala se desliza por el aire de ocho pisos de distancia $\mathrm{v}$

desciende en el aire la gravedad lo llama abajo se va raudo eternamente por ocho pisos de distancia entre la espiral de la escalera mientras duerme el ascensor en la vigilia iluminada por tubos de néon blanco la caja del edificio en la avenida que lleva el nombre del que fundara siglos ha la ciudad dondese edificio levanta sus ocho pisos de altura mientras duerme la gente del edificio en esa noche de domingo

'la noche mas nocturna y cansada

de la semana

¿o es la noche del sabado?

No sé, es en todo caso un fin de semana, y la primavera se asoma en este tiempo en que Roberto se deja caer y parece que no grita ¿O es que nadie lo oye? ¿O es que todos los oyen y prefieren colectivamente olvidar ese grito que se mezcla con los sueños de los dormidos? ${ }^{29}$

La experiencia de la muerte, un cuerpo que cae de un edificio sobre un piso de baldosas durante la primavera, es una imagen común del suicidio. Al mismo tiempo, el recurso mimético de la poesía visual que se aprecia aquí con la palabra «vertical» altera la clásica disposición gráfica del verso y recuerda este frágil equilibrio alterado entre texto y realidad que observamos en el poema «Ela, Elle, She, Lei, Sie». De esta manera, el texto insiste en un primer grado

28. Si el signo indica la ausencia de aquello que significa, entonces lo que queda es solo un aspecto del ser o incluso su muerte, puesto que el acto de ser es inmediato y no toleraría una mediación. Cfr. Maurice Blanchot, "la parole plurielle ", L'entretien infini, éd. Gallimard, Paris, 1969, p. 69.

29. Rodrigo Lira, "Cosas que suelen ocurrir en eternos instantes», Proyecto de Obras Completas, p. 51. 
de violencia hacia el lenguaje mismo, no solo por el sujeto enunciado, sino por la forma del enunciado. Ante la muerte del ser que equivale a la nominación que opera el signo, el poema propone una detención, un instante de caída que diluye la frontera entre pasado, presente y futuro, de manera que el hablante lleva al lector al límite de sus posibilidades lingüísticas. Desde entonces, los parámetros del tiempo no son fiables (como lo anuncia el oxímoron del comienzo) y el sentimiento de cercanía con el sujeto de la enunciación crece. $\mathrm{Al}$ mismo tiempo, la violencia hacia el hombre se plantea en este poema de dos maneras: primero, la violencia hacia la vida del individuo y la pérdida progresiva de su valor ontológico que representa la caída libre desde lo alto. Se denota en este texto el desprecio hacia el hombre; sus formas de vivir y de morir han sido alienadas del cuerpo social. La segmentación y división imposibilita la comunicación entre los hombres, prisioneros en la «caja». El «ascensor», elemento que potencialmente significa movilidad, no es operacional puesto que «duerme». Esta segmentación y falta de comunicación social producen el silencio y la indiferencia ante el fin trágico de Roberto, quien "parece que no grita». Segundo, la alienación social del individuo está presente en el rechazo a nombrar y a asumir esta pérdida humana y en el desprecio por parte de la colectividad. En el texto, la muerte de Roberto tiene diferentes versiones, todas oscuras, $-\_$Cae o se deja caer?- como testimonio de un lenguaje en el que no se puede confiar; sus aproximaciones deforman. Además, la alusión al fundador de la ciudad de Santiago (Pedro de Valdivia) reenvía a una imagen guerrera, violenta, de la época de la conquista. Finalmente, la ambigüedad en la participación de los otros identificados como «nadie», «todos» $\mathrm{y}$ «dormidos», simboliza el sometimiento colectivo ante la violencia y el posible olvido voluntario de su memoria: "prefieren colectivamente olvidar ese grito / que se mezcla con los sueños / de los dormidos».

Otro texto, que prefigura la violencia histórico-social, es "Comunicado», que citamos integralmente:

A la gente pobre se le comunica

Que hay cebollas para Ella en la Municipalidad de Santiago.

Las cebollas se ven asomadas a unas ventanas

Desde el patio de la I. Municipalidad de Santiago.

Tras las ventanas del tercer piso se divisan

Unas guaguas en sus cunas y por las que están un poco más abajo

Se ve algo de las Cebollas para la Gente Pobre.

Para verlas hay que llegar a un patio

Al patio con dos Árboles bien verdes

Después de pasar por el lado de una como jaula

Con una caja que sube y baja

Después de atravesar una sala grande con piso de baldosas

Y con tejado de vidrio

Con unas señoritas detrás de unos mostradores

Después de subir unas escaleras bien anchas

Después de pasar unas puertas grandes

En la esquina de una plaza que se llama

"de Armas", en la esquina del lado izquierdo 
De una estatua de un señor a caballo, de metal,

Con la espada apernada al caballo

Para que no se la roben y hagan daño.

Ahí, debajo de las ventanas con las guaguas,

Están las Cebollas.

No sé si se podrá conseguir

Unas poquitas.

El caballero que maneja

El ascensor ese, con paredes de reja.

Me dijo que eran para la gente pobre.

Después dijo algo del Empleo Mínimo.

Yo tenía que irme luego a comprar un plano de Santiago

Y una máquina de escribir. ${ }^{30}$

Este poema presenta un espacio estructurado por la voz del hablante. Recurso utilizado en muchos textos de Lira, la paráfrasis que convierte la totalidad del texto en una circunlocución sirve como de enmascaramiento del sujeto de la enunciación en una serie de posibilidades, en este caso topográficas. El sentimiento de desorientación espacial motivado por la circunlocución contrasta con la voluntad de precisión en el acto mimético que cumplen los enunciados. Un lugar preciso e institucional se vuelve así confuso e insondable en su espacialidad. De esta manera, la Municipalidad de Santiago posee esas irrisorias cebollas «asomadas» a una de sus ventanas que probablemente sean para la «gente pobre» pues no existe certeza («No sé si se podrá conseguir / Unas poquitas»). La descripción continúa con otros planos espaciales: las ventanas superiores, que sugieren a su vez la presencia de una sala cuna («Tras las ventanas del tercer piso se divisan / Unas guaguas en sus cunas»). Posiblemente el patio sea un elemento integrante del edificio en cuestión, o al menos hay que llegar a él para ver las cebollas y en consecuencia se continúa en el plano de las posibilidades.

La presentación de este recorrido laberíntico tiende entre el hablante y su destinatario (la "gente pobre») un proceso de identificación. La imbricación laberíntica de los espacios descritos niega al hablante un lugar de dominación, su voz no es una voz con autoridad, y todo se vuelve confuso tanto para él como para el lector. Su descripción es obscura por un exceso de celo en los detalles descritos. La voluntad de avisar a la gente pobre y de describir dónde se pueden conseguir las cebollas no concuerda con el desarrollo de la descripción confusa y el sentimiento de pérdida es compartido ( YYo tenía que irme luego a comprar un plano de Santiago»). El hablante se mimetiza así con el receptor, quien también se perderá en la lectura de este edificio municipal. En consecuencia, la topografía de la institución deviene un espacio complejo de barreras y trampas que el hablante presenta, ya sea comparativamente (la «jaula» que es «una caja que sube y baja» y que finalmente se identifica con el «ascensor») ya sea por indefinición o por medio de la alusión (la «sala grande con piso de baldosas / $\mathrm{Y}$ con tejado de vidrio» es un lugar impreciso con respecto a las «cebollas» $\mathrm{y}$

30. Rodrigo Lira, «Comunicado», Proyecto de Obras Completas, p. 31. 
«tejado de vidrio» alude a la transparencia pero también al símbolo popular para denotar ausencia de autoridad moral). Tampoco se aclara si «las señoritas detrás de unos mostradores» están para recibir gente o para impedir el paso de ella. En definitiva, todo indica que el hablante estuvo de paso por la institucionalidad; tránsito sin permanencia porque el espacio es potencialmente hostil, carcelario («jaula», "caja», "paredes de reja»). De esta forma, el hablante se pierde y pierde a sus destinatarios en la "I. Municipalidad de Santiago». Igualmente, otro símbolo violento o guerrero de identidad institucional y nacional se vuelve símbolo de alienación, puesto que la "estatua de un señor a caballo» deviene un objeto al cual se le puede robar la espada. Esta precaria situación de un símbolo histórico nacional sirve para la semiotización de la violencia impuesta por un orden que es rechazado, que no llega a internalizarse en la colectividad. La estatua, que además se encuentra en la plaza "de Armas», potencia esta semiótica de la violencia y la metonimia funciona para expresar el divorcio entre el relato histórico nacional y la memoria colectiva que reivindica una marginalización violenta de una parte de la población.

Terminaremos el análisis de textos con un fragmento de «Declaración». Corresponde a los textos que Lira escribe a partir de un material heterodoxo: críticas literarias hechas en la prensa o cartas que él envía a periódicos, a amigos o a otros poetas. Se trata de textos que escapan de manera evidente de la forma tradicional poética y que responden a un objetivo literario de experimentación con la transtextualidad y la transgresión de la tradición literaria:

Yo estaba más interesado en la Contemplación de la Luna majestuosa que en el inmediato entorno humano, de modo que fui sorprendido cuando se me interpeló en forma amenazante, siéndome solicitados mis documentos, los cuales habíanseme quedado en el departamento. Mientras los otros muchachos eran registrados también, se me hizo apoyar las manos sobre el poste para baloncesto que hay allí, más arriba de mi cabeza, con las piernas abiertas y se palpó toda la extensión de mi cuerpo.

[y]o había bebido aproximadamente entre 50 (cincuenta) y 75 (setentaicinco) centímetros cúbicos del mencionado trago, y alguien más bebió después de mí, acabando con el contenido de la botella, la cual alguien más se llevó; quiero decir que la noche de autos la gente iba y venía, y yo estaba ya marchándome a casa, soy muy parsimonioso para decir algo más que «salud» como saludo de despedida, y a veces «nos vemos", y otras veces "chao». De modo entonces que, al estar mis piernas en movimiento, y, por ende, mi persona toda, en el momento de la entrada en escena de los Agentes $[\ldots]^{31}$

Este fragmento, además de ser representativo de la estética liriana, basada en la experimentación y en un discurso híbrido, no tradicional, sirve para fundamentar lo anteriormente dicho de los otros textos citados. La representación de una intervención policial manifiesta una violencia evidente, sobre todo por la forma «amenazante». Fácilmente se puede interpretar esta acción como un símbolo de la representación de la dictadura. Sin embargo, su referente no se limita al periodo dictatorial. De hecho, no solo no se trata de una 
intervención policial ejercida antes, durante y después de la dictadura; sino que la forma, el lenguaje empleado, constituye un símbolo que denota otras formas de sometimiento y abuso de poder. El sujeto enunciado es nuevamente velado por una serie de formulaciones con cláusulas prescindibles. El exceso de detalles y de precisiones reiterativas vacía la capacidad comunicativa, como ocurre con el lenguaje administrativo o legislativo obligado a una retórica de iniciados. Las perífrasis asfixian el principio de claridad y la paranomasia tiene méritos en esto («cincuenta», «cúbicos», «acabando», "contenido», etc.). El desarrollo de oraciones con cláusulas explicativas innecesarias transmite una intención de ironizar sobre el discurso jurídico administrativo y así se revela la verdadera intención comunicativa (así por ejemplo la innecesaria descripción sobre las distintas formas de despedirse o de precisar que porque sus piernas se movían, todo su cuerpo seguía aquel movimiento). El texto reanima en definitiva otro símbolo colectivo: el discurso solemne de la ley y de las instituciones que, fingiendo obrar en beneficio de los ciudadanos, legalizan y simbolizan, en su misma configuración, el uso de la violencia contra la sociedad.

\section{Conclusiones}

Los textos y libros publicados o escritos en periodos de crisis son factibles de ser interpretados como claves para el estudio del contexto de censura, violencia o revoluciones en que fueron producidos. Es lo que el análisis sociológico de la literatura ha aportado con sus métodos a la crítica literaria. A pesar de lo anterior, la dificultad mayor radica en el correlato y aproximación entre el análisis social del contexto en cuestión y de la obra analizada. De la adecuación entre estos dos sistemas de lectura -cada uno con sus propias variablesdependerá la pertinencia con los textos y con la problemática planteada por los investigadores. El análisis de la obra de Lira ha sido determinado antes de tiempo por una serie de afirmaciones que no podían abstraerse lo suficiente del contexto dictatorial en que fue mayoritariamente escrita. Del mismo modo, las características propias de la obra no facilitan la independencia del análisis con respecto al autor de los textos, ya que generalmente nos encontramos con un hablante que autobiográficamente registra anécdotas personales. Sin embargo, actualmente y a la luz de las investigaciones realizadas ulteriormente sobre aspectos de la identidad nacional ${ }^{32}$, es posible confrontar conclusiones críticas que se basaban en el contexto especial de la poesía de los años ochenta en Chile. En definitiva, el riesgo es promover a una época excepcional con una lectura excepcional que trasciende al estudio del texto literario para "anclarlo» en un contexto particular.

En el caso específico de la obra de Lira, hemos expuesto aquí una interpretación textual de sus posibilidades en la recepción que restituyen su valor

32. Cf. Rafael Gaune y Martín Lara (eds.), Historias de Racismo y Discriminación en Chile, 2009. 
universal en cuanto desarrolla una poesía de la circunstancia que, paradojalmente, restituye una memoria universal de la violencia. El análisis revela esta estrategia discursiva que se extiende a la totalidad de la obra de Lira por medio de la experimentación con distintos tipos de lenguajes, como el lenguaje familiar, el recurso de la anécdota, la ironía y el juego con el traspaso y amalgama de los límites contextuales en el texto. Dicha estrategia posibilita la analogía entre el hablante y el lector. En esta analogía, la semiotización de actos de abuso o coercitivos es el lugar de encuentro entre la obra y la memoria colectiva de hechos de exclusión que no son privativos de una época o nación, pero que son obviados por el relato oficial de la historia. Así, se demuestra, como anunciamos, que la simbolización de la violencia en esta obra no es exclusiva del contexto de la dictadura, hecho que explicaría la sintonía entre los lectores y esta poesía.

\section{Bibliografía}

Andrew Barash Jeffrey, "Qu'est-ce que la mémoire collective ? Réflexions sur l'interprétation de la mémoire chez Paul Ricœur ", Revue de Métaphysique et de Morale, 2006/2 ( $\mathrm{n}^{\circ}$ 50), 185-195.

Baeza C. Jorge, «Referencias para un análisis del discurso del gobierno militar chileno sobre el movimiento estudiantil universitario: 1973-1980», Literatura y Lingüística, 2004, n 15, pp. 256-286.

Barthes Roland, Le degré zéro de l'écriture, Paris, Seuil, (1953) 1972, 179 p.

Blanchot Maurice, «La parole plurielle», L'entretien infini, Paris, Gallimard, 1969, $672 \mathrm{p}$.

De la Fuente Antonio, «Trinitariamente pergueñando al infinito», La Bicicleta, $\mathrm{n}^{\circ} 19$, p. 36.

Eco Umberto, L'œuvre ouverte, Paris, Seuil (1965) 1979, 314 p.

Forget Danielle, «L'ironie: stratégie de discours et pouvoir argumentatif», Études Littéraires, 2001, vol 33/1, pp. 41-54.

Gaune Rafael et Lara Martín (eds.), Historias de Racismo y Discriminación en Chile, ed. Uqbar, 2009, 396 p.

Kristeva Julia, La révolution du langage poétique, Paris, Seuil, 1974, 341 p.

Lihn Enrique, "Prólogo», en Lira Rodrigo, Proyecto de Obras Completas, Editorial Universitaria, 2003, $10 \mathrm{p}$.

Lira Rodrigo, Proyecto de Obras Completas. Editorial Universitaria, (1983) 2003, 153 p.

- Declaración Jurada, Ediciones Universidad Diego Portales, 2006, 97 p.

Merino Roberto, «Nota a la segunda edición», en Lira Rodrigo, Proyecto de Obras Completas, Editorial Universitaria, 2003, 3 p.

Morales Leónidas, «Joaquín Edwards Bello: Crónica y Crítica de la Vida Cotidiana Chilena», en Revista Chilena de Literatura, 2009, n 74, $21 \mathrm{p}$.

Ricœur Paul, La mémoire, l'histoire, l'oubli, Paris, Seuil, 2000, 676 p.

Rojas Gonzalo C., « Dos poetas de los ochenta: Juan Luis Martínez y Rodrigo Lira. Autorreferencia y fragmentación ", in Cyber Humanitatis [En línea], Universidad de Chile. [Pág. consultada el 30 de abril de 2012]. Disponible en:

http://www.cyberhumanitatis.uchile.cl/index.php/RCH/article/viewArticle/5647/5515 Rojo Grinor, «Prólogo», en Lira Rodrigo, Declaración Jurada, Ediciones Universidad Diego Portales, 2006, 9 p. 